\title{
MACROSCOPIC AND MICROSCOPIC INTERMESENTERIC COMMUNICATIONS
}

\author{
David Kachlik, Vaclav Baca
}

\author{
Department of Anatomy, $3^{\text {rd }}$ Medical Faculty, Charles University, Praha, Ruska 87, 10000 \\ e-mail:david.kachlik@lf3.cuni.cz
}

Received: January 16, 2006; Accepted: March 3, 2006

Key words: Mesenteric/Intermesenteric/Anastomosis/Injection/Arterial/Microcirculation

The aim of this study was to describe all levels of the intermesenteric communications because of their importance in vascular diseases of the colon. The connections of superior and inferior mesenteric networks are very important in cases of acute or chronic obstruction to prevent ischemia and necrosis. Angiograms of mesenteric arteries were studied (40), cadaverous large intestine samples with mesentery and feeding vessels were dissected (36) or injected with India ink solution (24) or methylmetacrylate Mercox (41). In $7.9 \%$ of cases an intermesenteric connection was described, named anastomosis intermesenterica accessoria and classified according to Pikkieff's ${ }^{1}$ proposal. The marginal artery in the left colic flexure forms an arch called Riolan's arcade ${ }^{2}$ or Haller's anastomosis ${ }^{3}$ and is present in $95 \%$ of cases. Infrequent anastomosis between straight vessels and mighty plexuses in the intestinal wall were registered. There are no regional differences when compared to the rest of colon.

\section{INTRODUCTION}

Mutual connections between superior and inferior mesenteric arterial networks are important in both acute and chronic obstructions of the large intestine. The most afflicted spot is the cranial part of the superior mesenteric artery, caused mainly by atherosclerotic stenosis. This is demonstrated either by a clinically silent state, appears as chronic abdominal anginous pain or sudden thrombotic disorder, or as an acute embolic attack. Tumorous metastasis in lymph nodes is able to compress the vessels, too. The presence, lumen, frequency and level of anastomosis and possible growth of collaterals are the limiting factors of such afflictions. This is a reason for mapping the frequency of intermesenteric anastomosis in Czech population.

\section{MATERIAL AND METHODS}

Parts of the large intestine were dissected including its arterial supply in the extent of the whole artery from its origin to the branching in arteriolae rectae. Material was obtained from cadavers dissected at the Department of Anatomy, $3^{\text {rd }}$ Medical Faculty, Charles University (36 bodies, aged 56-81). Angiograms of both mesenteric arteries, stored in the archive of the Department of Anatomy (11 samples) and lent by Radiological Department of the Faculty Hospital at Královské Vinohrady (29 samples) were examined too. In addition, 24 samples of colon tissue including feeding vessels were cut out of cadavers at Department of Pathology of the Faculty Hospital at Královské Vinohrady (aged 41-92). After rinsing and cleaning, dissecting and canulating the feeding vessels, the network was flushed with lukewarm saline $\left(20^{\circ} \mathrm{C}\right)$ and then saline was replaced with India ink solution. Ligated samples were preserved in $8 \%$ formalin solution for 10 days and then dissected.

Another 41 samples from the pathological ward (age 30-88) were injected with commercially produced methylametacrylate called Mercox CL-2B (Ladd Research Industries, Burlington, VA), after the same procedure as for the previous India ink injections. When injected the samples were stored in warm water $\left(45-50{ }^{\circ} \mathrm{C}\right)$ for polymerization for $24 \mathrm{~h}$, then put in $30 \%$ kalium lye $\left(50{ }^{\circ} \mathrm{C}\right)$. Rinsed and dried casts were deep-frozen, cut, refined and dried again, then vaporized with gold powder and scanned in electronic microscope (S 5120.1 Proxima - Aquasem). No pathological changes were found in the samples.

\section{RESULTS}

In the macroscopic part (a total of 76 samples) a mighty vessel connecting both mesenteric arteries was identified in the dissected bodies only once and in angiograms five-times (Fig. 1). As for total amount of the macroscopically examined samples it rates $7.9 \%$. The vessel calibre was always very large, close to main colic branches diameter. There were no principal similarities in all six cases, which is why the qualitative division made by Pikkieff ${ }^{1}$ was applied.

Two samples corresponded to type IIa (Fig. 2a) (connection between the midpoint of middle colic artery length and the midpoint of left colic artery), other two angiograms correspond to type IIb (Fig. 2b) (connection between the midpoint of middle colic artery length and the origin of left colic artery) and one angiogram and 
one sample resembled type IIc (anastomosis between the lower third of middle colic artery and upper third of left colic artery). There was no connection between either accessory middle colic artery or accessory left colic artery.

As for microcirculatory level, infrequent anastomosis between arteriolae rectae and frequent ones within subserous plexus were found on India ink injections. Mighty constant plexuses in all intestinal wall layers were to be found on methylmetacrylate casts. Especially submucous plexus forms a massive possible collateral canal. The dimensions and frequency of all plexuses don't differ from those in the rest of the colon (Fig. 3, 4, 5).

\section{DISCUSSION}

Interconnections between both mesenteric networks are divided in four levels. The first one is a large intermesenteric anastomosis, present in approximately $10 \%$. Firstly drawn by Mascagni ${ }^{4}$, mentioned by Corsy ${ }^{5}$, first name adopted by Villemin ${ }^{6}$ as ,anastomose central intermésentérique“, it was widely described by Pikkieff ${ }^{1}$ (1931) who was the only one to use the term of „anastomosis accessoria“. Later authors called it „intermesenteric arcade“, Vandamme ${ }^{7}$ applied the term of „arcus intermesentericus", and some others even adopted the expression of „Riolan arc“ by Grant and Basmajian". On the contrary Andrejew ${ }^{9}$, Huard ${ }^{10}$, Pikkieff ${ }^{1}$ and Testut ${ }^{11}$ used „Riolan arc“ as well as renowned medical dictionaries ${ }^{12,13}$ and even some recent authors ${ }^{14}$ apply the expression of „intermesenteric arterial arch / arcade“ in the meaning of part of the marginal artery in the area of the left colon flexure. This misunderstanding dates back to Riolan whose description of the colon is very inexact but his

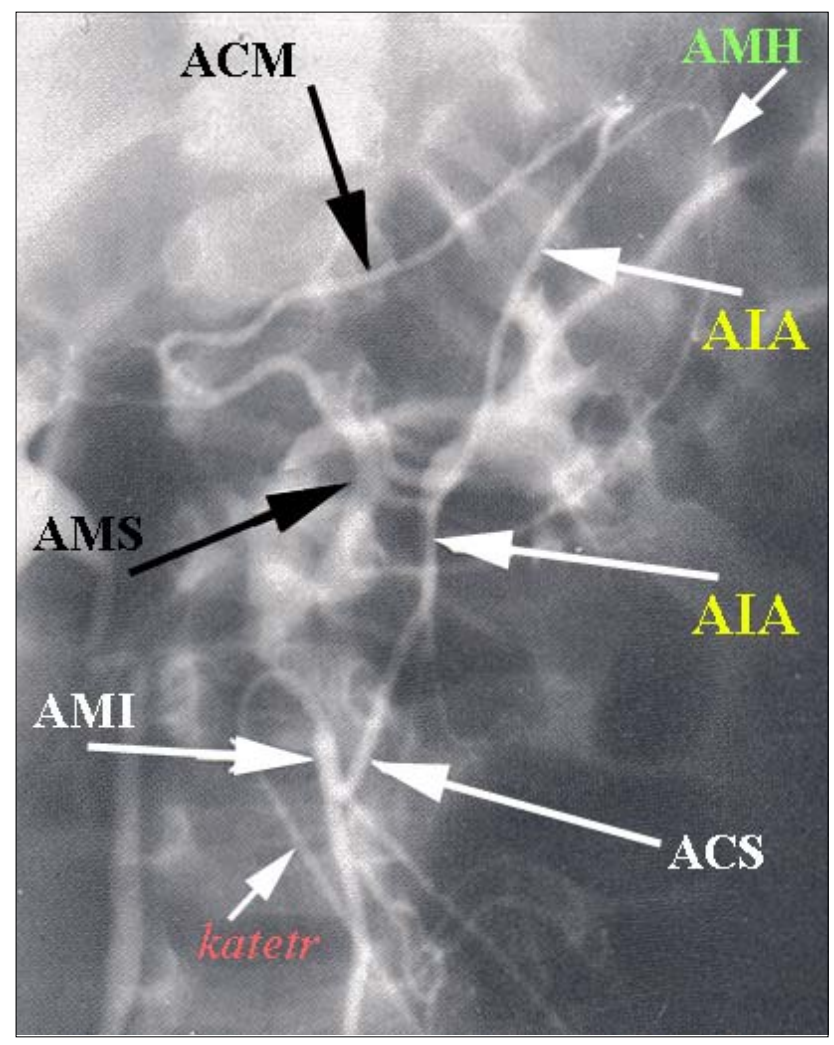

Fig. 1. Angiogram of the anastomosis intermesenterica accessoria.

drawings show a vessel now called the arteria marginalis coli Drummondi ${ }^{15}$.

To differentiate between the anastomosis magna Halleri and the intermesenteric connection the name of „anastomosis parva“ has been suggested. Although „par-

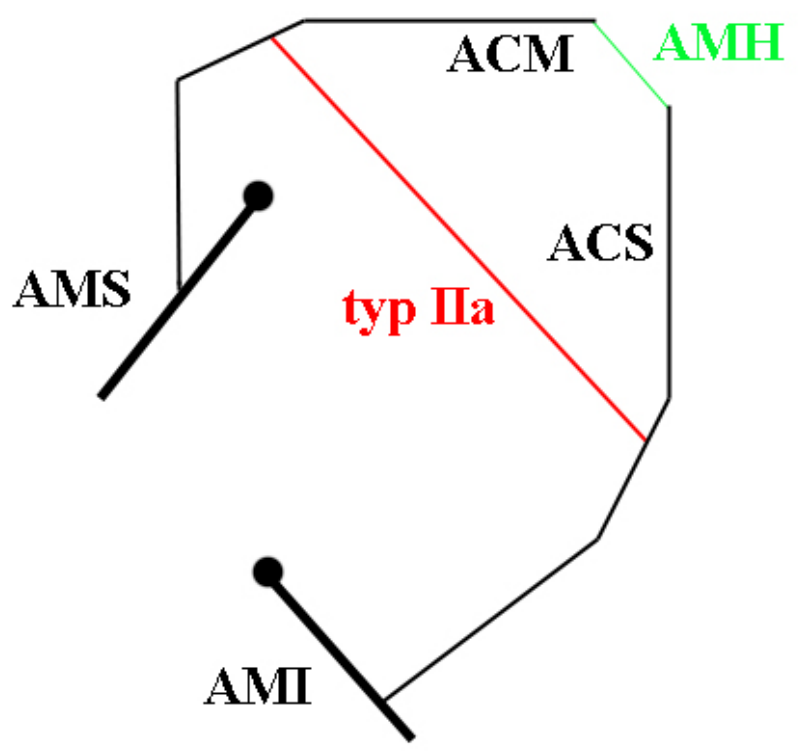

Fig. 2a. Type IIa of anastomosis intermesenterica accessoria according to Pikkieff's division.

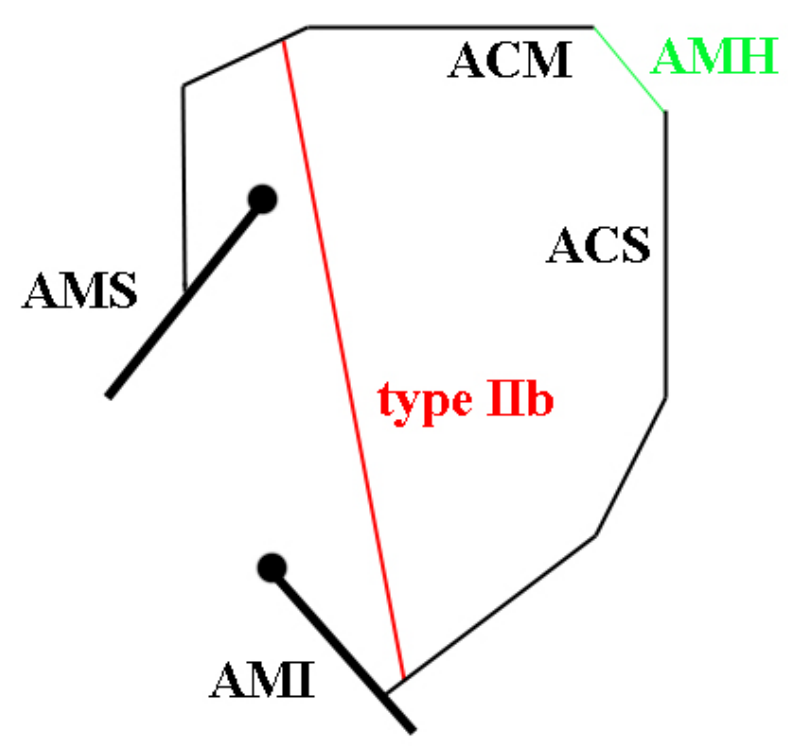

Fig. 2b. Type IIb of anastomosis intermesenterica accessoria according to Pikkieff's division. 


\section{Legend to figures}

AMS $=$ arteria mesenterica superior

AMI = arteria mesenterica inferior

$\mathrm{ACM}=$ arteria colica media

ACS = arteria colica sinistra

AIA = anastomosis intermesenterica accessoria

$\mathrm{AMH}=$ anastomosis magna Halleri

$\mathrm{A}=$ artery

$\mathrm{V}=$ vein

$\mathrm{vR} \quad=$ vasa recta

$\mathrm{vM}=$ vasa marginalia

$\mathrm{C}=$ Lieberkühn's crpyts

a $\quad$ artefact

$\mathrm{Mu}=$ plexus mucosus

$\mathrm{SM}=$ plexus submucosus

vus" could evoke a shorter vessel, its lumen is often wider and the anastomosis is absent in $90 \%$. On this account we strongly suggest the unambiguous expression of anastomosis intermesenterica accessoria or accessory intermesenteric anastomosis in English according to following rules (stated by Williams ${ }^{16}$ (1957)). The eponym referring to this term is Villemin ${ }^{6}$.

This vessel connects either superior and inferior mesenteric trunk or, more frequently, their branches in the mesentery, close to its root, never in its peripheral margin. It is not part of the marginal artery, and there are no straight arteries arising from it. It runs close to the inferior mesenteric vein and forms second, accessory arterial arch, bending along the duodenojejunal flexure and traversing the ligamentum suspensorium duodeni anteriorly.

Its frequency varies from $0 \%$ to $18 \%$ (García-Ruiz $^{17}$ $0 \%$, Bamsajian ${ }^{8} 5.7 \%$, Hovelacque ${ }^{18} 5 \%$, Huard ${ }^{10} 6 \%$, Pikkieff $9 \%$ to $10 \%$, Renner ${ }^{14} 9.6 \%$, Griffiths ${ }^{19} 10 \%$, Williams $^{16} 11 \%$, Vandamme ${ }^{20,21} 12 \%$, Villemin ${ }^{6} 18 \%$ ). The half of the anastomosis lumen samples is similar to connected arteries, the other half is narrower.

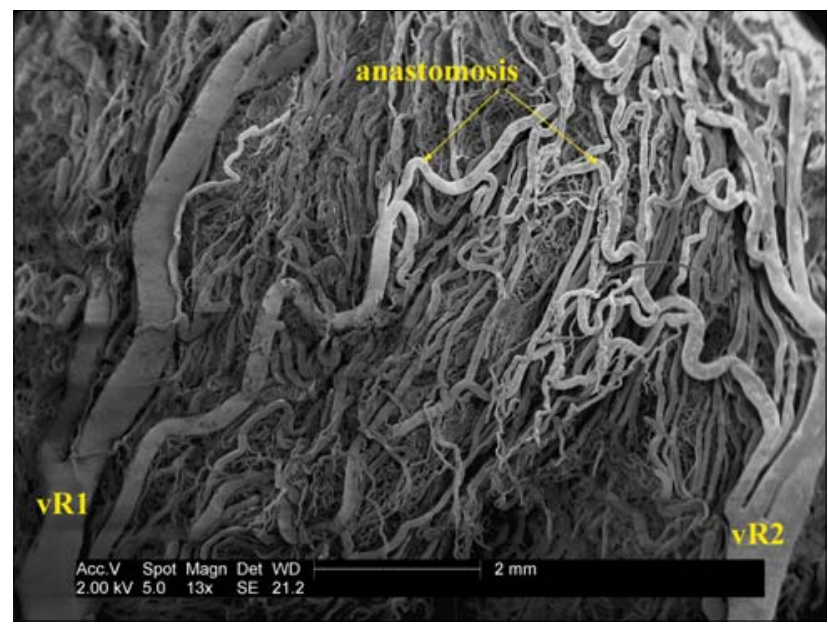

Fig. 4. Vasa recta and plexus subserosus on the Mercox corrosion cast.

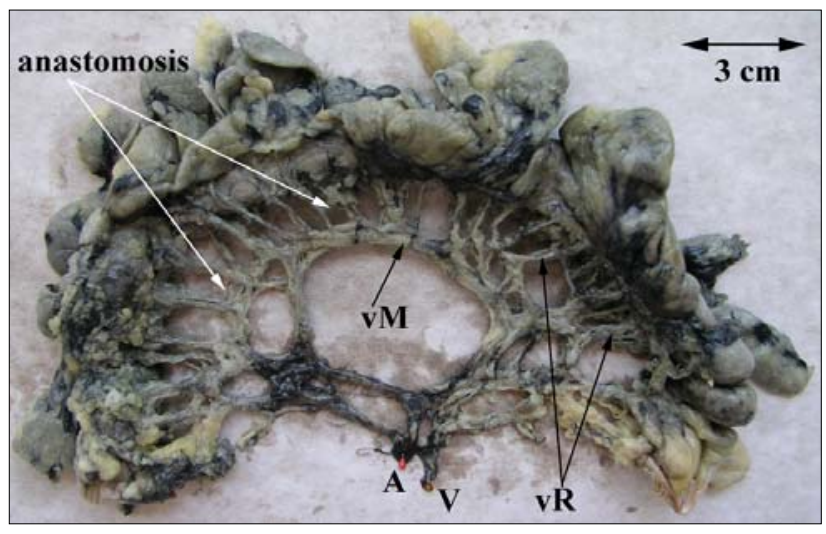

Fig. 3. Marginal and straight vessels on the India ink injected sample.

Pikkieff has proposed the type division which the authors agree to:

I - connection between the accessory middle colic artery and the left colic artery $-5.7 \%$

II - communication between the middle colic artery and the left colic artery - $3 \%$

III - anastomosis between trunks of both mesenteric arteries $-0.3 \%$

IV - vessel connecting superior mesenteric artery and left colic artery $-0.3 \%$

The term Arcus Riolani, Riolan's arcade or arch refers to that part of the colic marginal artery situated in the area of left colic flexure unambiguously, it is identical to the expression of anastomosis magna Halleri. This is the second level of intermesenteric communications as a short part of a long channel called by Drummond ${ }^{15}$ (1913), macroscopically detectable in $95 \%$ with various calibres (Steward ${ }^{22}$ states its $100 \%$ presence). Also secondary and tertiary arcades respectively, if present belong to this level. The most frequent ones are at main arteries branching points.

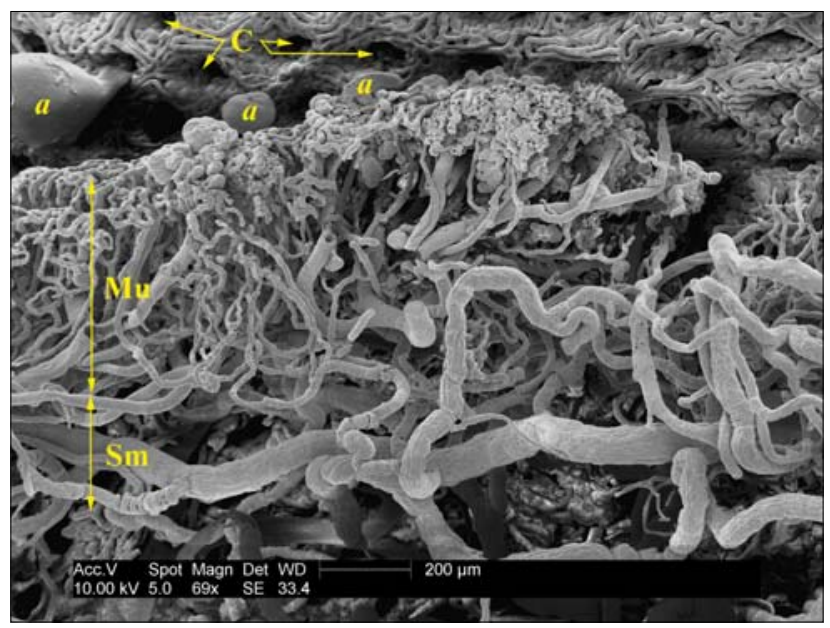

Fig. 5. Submucosal and mucosal plexus on the Mercox corrosion cast. 
The last, equally important but not the least level is the microcirculatory network. Except infrequent anastomosis between arteriolae rectae there are constant mighty plexuses in all colon wall layers. Sparse subserous network is derived from both long and short straight arteries. The second plexus is stretched between circular and longitudinal muscular layer, the third, a massive one, is submucous, supplying both muscular and the innermost, mucous, tiny meshwork sending capillaries around the intestinal crypts. In normal state these plexuses feature no regional differences throughout the whole length of colon.

\section{CONCLUSION}

From the morphological point of view there is a connection between both mesenteric networks, in all cases at the macroscopic level nearly and constantly at the microcirculation level. For the intermesenteric communication close to the arteries roots (present in 5-10\%) the term anastomosis intermesenterica accessoria is strongly suggested. The question is if the anastomosis is able to replace the source of arterial blood supply in the case of acute obstruction. Finally it is to remind that expressions Riolan's arch and Haller's anastomosis are identical and cannot be mistaken for anastomosis intermesenterica accessoria. The following conclusion is important for possible collateral circulation: the number and frequency of anastomosis increase with growing distance from aorta.

\section{REFERENCES}

1. Pikkieff H. (1931) Über die Blutversorgung des Dickendarms Zschr Anat Entw 96, 658-79.

2. Riolan J Jr. Opuscula anatomica nova. London: Fresher, 1649.

3. Haller A. Icones anatomicae in quibus praecipue alique partes corporis humani delineatae proponuntur et arteriarum potissimum historia contineatur. Gottingen: B. Abram Vandenhoek, 1756.
4. Mascagni P. Vasorum Lymphaticorum Corporis Humani Historia et Iconographia. Senis: Pazzini Carli, 1787.

5. Corsy E, Aubert A. (1913) Artères de l'intestin grêle et des colon. Bibliographie anat, 23, 221-54.

6. Villemin F. (1920). Sur l'existence d'une anastomose entre les deux artères mésentériques. Hypothèse embryologique. C r Séanc Soc Biol 83, 439-40.

7. Vandamme JP, van der Schuren G. (1976) Re-evaluation of the colic irrigation from the superior mesenteric artery. Acta Anat (Basel) 95, 578-88.

8. Basmajian JV. (1954) The marginal anastomoses of the arteries to the large intestine. Surg Gyn And Obst 99, 614-6.

9. Andrejew JD. (1931) Über den Recessus arcus Riolani, den Recessus a. colicae sinistrae, und die Beziehungen der Bauchfelltaschen des Mesogastrium zu den Blutgefässen. Anat Anz 71, 135-55.

10. Huard P. (1939) L'anastomose centrale intermésentérique. Ann d'Anat Path 16, 805-7.

11. Testut L. Trattato di anatomia umana II. Torino: U. T. E. T., 1902.

12. Dorland's Illustrated Medical Dictionary (under names) $24^{\text {th }}$ edition. Philadelphia and London: WB Saunders Company, 1965.

13. Stedman's Medical Dictionary. Baltimore: Williams and Wilkins Company, 1953.

14. Renner K, Ausch C, Rosen HR et al. (2003) Die kollaterale Gefassversorgung des linken Hemikolons: Historische Beobachtungen und aktuelle klinische Bedeutung. Chirurg. 74, 575-8.

15. Drummond H. (1913) Some points relating to surgical anatomy of arterial supply of large intestine. Proc Roy Soc Med 7, 185-93.

16. Williams GH, Klop EJ Jr. (1957) Intermesenteric arterial communications. Univ Michigan M Bull, 23, 53-7.

17. García-Ruiz A, Milsom JW, Ludwig KA, Marchesa P. (1996) Right colonic arterial anatomy. Implications for laparoscopic surgery. Dis Colon Rectum, 39, 906-11.

18. Hovelacque A. Les artères mésentériques. Paris: Doin Édit., 1936.

19. Griffiths JD. (1961) Extramural and intramural blood supply of the colon. Br Med J 4, 323-6.

20. Vandamme JP, Bonte J, van der Schueren G. (1982) Re-evaluation of the colic irrigation from the inferior mesenteric artery. Acta Anat (Basel) 112, 18-30.

21. Vandamme JP, van der Schuren G. (1976) Re-evaluation of the colic irrigation from the superior mesenteric artery. Acta Anat (Basel) 95, 578-88.

22. Steward JA, Rankin FW. (1933) Blood supply of the large intestine. Arch. Surg. 26, 843-891. 